\title{
AN INSIGHT INTO ANATOMICAL VARIATIONS IN MAXILLARY MOLARS: A CASE SERIES
}

Manisha Nepal, Vanita Gautam, ${ }^{1}$ Snigdha Shubham, ${ }^{1}$ Rupam Tripathi, ${ }^{1}$ Rinku Sah ${ }^{1}$

\begin{abstract}
The aim of this article is to show different anatomic complexities of the root canal system related to maxillary molars. Maxillary molars are presumed to have only three roots with three canals but this is not always the case, it might present with different variations. Some of the anatomical variations such as, mesiobuccal2 (MB2) canals in maxillary $1^{\text {st }}$ and $2^{\text {nd }}$ molars, two rooted maxillary $1^{\text {st }}$ and $2^{\text {nd }}$ molar, one rooted maxillary $2^{\text {nd }}$ molar, C-shaped upper $2^{\text {nd }}$ molar and maxillary $2^{\text {nd }}$ molar with extra palatal root are reported in this case series. Hence, in treating each tooth every dentist must keep foresight that complex anatomy occurs often enough to be considered normal and manage them accordingly.
\end{abstract}

KEYWORDS Anatomical variations, extra palatal root, maxillary molars, mesiobuccal

1. Department of Conservative Dentistry and Endodontics, Universal College of Medical Sciences, Bhairahawa, Nepal DOI: https://doi.org/10.3126/jucms.v6i2.22502

\author{
For Correspondence \\ Dr. Manisha Nepal \\ Dept. of Conservative Dentistry and Endodontics \\ Universal College of Medical Sciences \\ Bhairahawa, Nepal \\ Email:manisha.nepal.mn@gmail.com
}




\section{INTRODUCTION}

Anatomical variations frequently encountered may present challenges for cleaning, shaping and obturation. The several anatomic variations that might exist in the root canal system have contributed to endodontic treatment failures. ${ }^{1}$ The maxillary $1^{\text {st }}$ molar is the largest tooth in volume and one of the most complex in root and canal anatomy. ${ }^{2}$ Maxillary first molars have exhibited a frequent radicular anatomy of 3 roots and 3 or 4 canals. ${ }^{3}$ Maxillary $2^{\text {nd }}$ molar root and canal anatomy are similar to those of the $1^{\text {st }}$ molar, although variations may frequently occur. ${ }^{4}$ Three separate roots and three separate canals is common occurrence but the variation may be three separate roots and four canals (two in the mesiobuccal root) that is less likely to be present than $1^{\text {st }}$ molars; two separate roots with a single canal in each; one main root and canal; and four separate roots and four separate canals including two palatal.

\section{CASE REPORT}

During the endodontic treatment in the Department of Conservative Dentistry and Endodontics, UCDS, Ranigaon, Bhairahawa, the following anatomical variations in maxillary molars were observed.
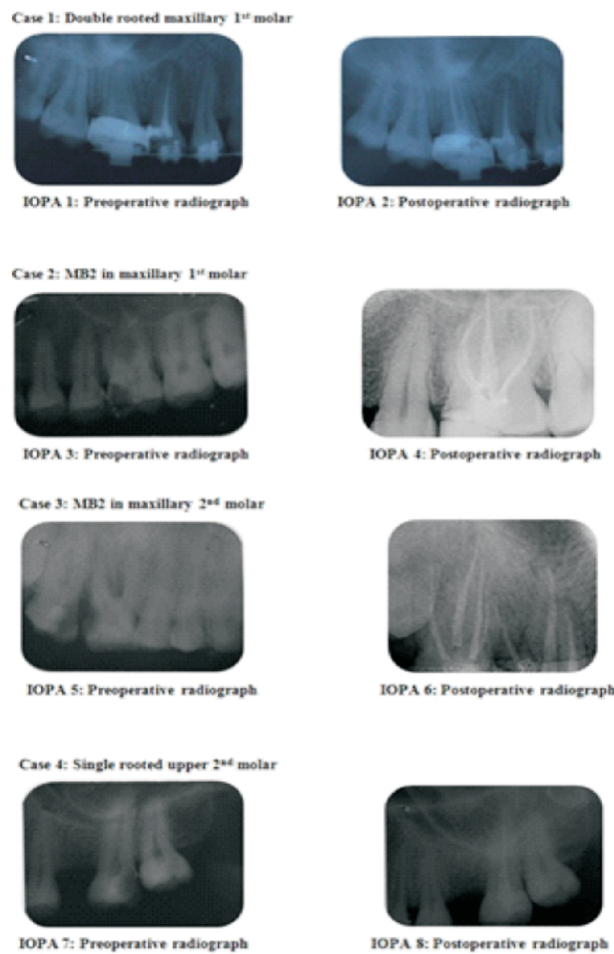

Figure 1.Double rooted maxillary $1^{\text {st }}$ molar (IOPA 1 and 2), MB2 in maxillary $1^{\text {st }}$ molar (IOPA 3 and 4), MB2 in maxillary $2^{\text {nd }}$ molar (IOPA 5 and 6), single rooted upper $2^{\text {nd }}$ molar (IOPA 7 and 8)
Intraoral periapical radiographs (IOPA) 1 to 14 depicts the following cases respectively: Double rooted maxillary $1^{\text {st }}$ molar (IOPA 1 and 2), MB2 in maxillary $1^{\text {st }}$ molar (IOPA 3 and 4), MB2 in maxillary $2^{\text {nd }}$ molar (IOPA 5 and 6), Single rooted upper $2^{\text {nd }}$ molar (IOPA 7 and 8) \{Figure 1\}, Double rooted maxillary $2^{\text {nd }}$ molar (IOPA 9 and 10), Extra Palatal root in maxillary $2^{\text {nd }}$ molar (IOPA 11 and 12 ), C-shaped $2^{\text {nd }}$ molar (IOPA 13 and 14) (Figure 2)

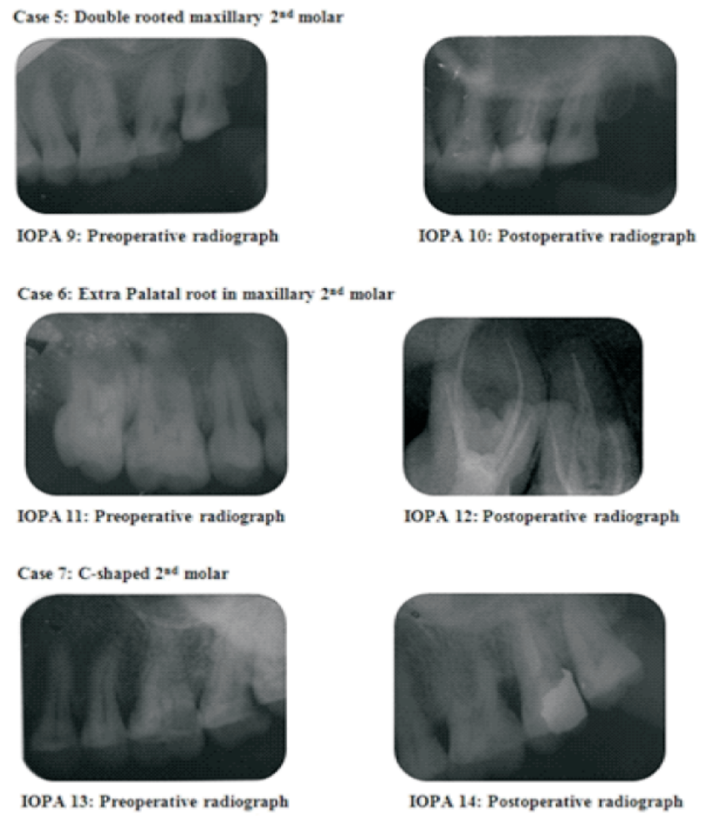

Figure 2. Double rooted maxillary $2^{\text {nd }}$ molar (IOPA 9 and 10), Extra Palatal root in maxillary $2^{\text {nd }}$ molar (IOPA 11 and 12), C-shaped $2^{\text {nd }}$ molar (IOPA 13 and 14)

\section{DISCUSSION}

Knowledge of the most common root canal configuration as well as their anatomic deviations allows for more effective cleaning and shaping, which have been associated with higher success rates. An inability to recognize the presence of and to adequately treat all of the canals of the root canal system has been attributed to be the major cause of root canal treatment failure. Blaine et al reported over $399(95.9 \%)$ of maxillary molars had three roots and $16(3.8 \%)$ had two roots. ${ }^{6}$ Likewise Al Shalabi et al. reported only 2 out of 83 teeth $(2.4 \%)$ studied had two roots. ${ }^{7}$ The two root form is rarely reported and may be due to the fusion of the distobuccal root to the palatal root or the fusion of $\mathrm{DB}$ root to the $\mathrm{MB}$ root. The $\mathrm{MB}$ root of maxillary $1^{\text {st }}$ molar contains a double root canal system more often than a single canal according to most of the anatomic studies. Vertucci F demonstrated 55\% teeth with MB2 canal by clearing technique. ${ }^{8}$ Likewise, Çaliskan, MK et al using clearing technique reported that $66 \%$ had MB2 canals.' 
The anatomical studies found a wide range of MB2 canal incidence in upper $2^{\text {nd }}$ molar. Ingle et al reported $47.1 \%$ (1273 out of 2705) had MB2 canals in upper second molar. ${ }^{4}$ Pecora studied the internal anatomy of 370 maxillary molars by clearing the roof of the pulp chamber and located a second canal in mesiobuccal root of maxillary second molars, with frequency of $42 \%{ }^{3}$

Out of 1272 teeth studied, majority of maxillary second molars presented with 3 roots $(88.6 \%)$. However, $2.8 \%, 7.8 \%$ and $0.4 \%$ of maxillary second molars presented with one, two and four roots respectively. ${ }^{4}$ Peikoff et al conducted a retrospective study of 520 endodontically treated maxillary $2^{\text {nd }}$ molars and reported $3.1 \%$ teeth with one main root and canal, $6.9 \%$ with two separate roots with a single canal in each and $1.4 \%$ four separate roots with extra palatal root. ${ }^{10}$ Al Shalabi et al reported 6 out of $40(15 \%)$ had 2 roots but their study did not find maxillary second molars with single root and extra palatal root. $^{7}$

$\mathrm{C}$-shaped anatomies are uncommon in upper molars. The first authors to describe a maxillary C-shaped molar were Newton and McDonald, who, in the year 1984, described a C-shaped canal appearance connecting both distobuccal and palatal root canals linked in the pulp chamber floor to the mesiobuccal root canal by developmental grooves. ${ }^{11}$ Martins et al demonstrated 49 teeth presented C shapes out of 1299 second molars, which represents a prevalence of $3.8 \%{ }^{11}$

\section{CONCLUSION}

Deviation from normal expected anatomy often exists which may complicate the endodontic procedure of cleaning, shaping and obturation. Hence, in treating each tooth every dentist must keep foresight that complex anatomy occurs often enough to be considered normal and manage them accordingly.

\section{ACKNOWLEDGEMENTS}

I would like to acknowledge all the patients and technical staffs who were involved directly or indirectly to this study.

\section{REFERENCES}

1. Favieri A, De Barros FGB, Campos LC. Root canal therapy of a maxillary first molar with five root canals: Case report. Braz Dent J. 2006;17(1):75-8.

2. Hargreaves KM, Cohen S. Cohen's Pathways of the Pulp. 2012.

3. Pécora J, Woelfel J, Sousa Neto M, Issa E. Morphologic study of the maxillary molars. Part II: Internal anatomy. Braz Dent J. 1992;3(1):53-7.
4. Ingle JI, Bakland LK, Baumgartner JC. Ingle's Endodontics 6 . In: 6th ed. CBS Publishers and Distributors Pvt. Ltd; 2008.

5. Wolcott J, Ishley D, Kennedy W, Johnson S, Minnich S, Meyers $\mathrm{J}$. A $5 \mathrm{yr}$ clinical investigation of second mesiobuccal canals in endodontically treated and retreated maxillary molars. J Endod. 2005;31(4):262-4.

6. Cleghorn BM, Christie WH, Dong CCS. Root and Root Canal Morphology of the Human Permanent Maxillary First Molar: A Literature Review. J Endod. 2006;32(9):813-21.

7. al Shalabi RM, Omer OE, Glennon J, Jennings M, Claffey NM. Root canal anatomy of maxillary first and second permanent molars. Vol. 33, International Endodontic Journal. 2000. p. 405-14.

8. Vertucci F. Root canal anatomy of the human permanent teeth. Oral. Surg Oral Med Oral Pathol. 1984;58:58999.

9. Calişkan MK, Pehlivan Y, Sepetçioğlu F, Türkün M, Tuncer SS. Root canal morphology of human permanent teeth in a Turkish population. J Endod [Internet]. 1995;21(4):2004. Available from: http://www.ncbi.nlm.nih.gov/pubmed/767382

10. Peikoff MD, Christie WH, Fogel HM. The maxillary second molar: variations in the number of roots and canals. Int Endod J. 1996;29:365-9.

11. Martins JNR, Mata A, Marques D, Anderson C, Caramês J. Prevalence and characteristics of the maxillary C-shaped molar. JEndod. 2016;42(3):383-9. 